Gut, 1969, 10, 769-773

\title{
Measurement of blood and iron loss in colitis with a whole-body counter
}

\author{
B. H. R. STACK, T. SMITH ${ }^{1}$, J. HYWEL JONES, AND J. FLETCHER \\ From University College and St Mark's Hospitals, London
}

SUMMARY Estimation with a whole-body counter of the fall in total body radioactivity due to loss of parenterally administered ${ }^{59} \mathrm{Fe}$ has been used to measure blood loss in 17 patients with ulcerative colitis. It was shown that blood loss was related to the activity of disease as judged by sigmoidoscopic changes and less obviously to the extent of involvement of the colon.

Blood losses of 50 to $150 \mathrm{ml}$ per week were observed when the patient saw no blood in the stools and the rectal mucosa did not appear haemorrhagic.

Some patients lost more than $0.5 \mathrm{~g}$ iron during the few weeks following an exacerbation of ulcerative colitis suggesting that repeated replacement of the body's iron stores is often necessary in this disease.

Iron-deficiency states occur commonly in proctocolitis and have been shown to be due mainly to loss of blood into the gastrointestinal tract (Ormerod, 1967). Blood loss can be quantitated by injecting intravenously red blood cells labelled with ${ }^{51} \mathrm{Cr}$ and then measuring the amounts of radioisotope passed in the stool (Bannerman, 1957) or by chemically estimating the faecal haemoglobin content (Ebaugh and Beeken, 1959; Ormerod, 1967). Since these methods involve the collection of all the stool passed during the period of investigation, they are impracticable for long-term outpatient studies and liable to inaccuracy in patients with severe diarrhoea, urgency of defaecation, and incontinence.

In this study we have used a technique for measuring blood loss which avoids the need for stool collection. This method is similar to that described by Price, Reizenstein, Cohn, Cronkite, and Wasserman (1961) and more recently by Holt, Mayet, Warner, and Callender (1967), and is based on the fact that in normal men loss of iron from the body is very small, on average $0.6 \mathrm{mg}$ per day (Finch, 1964), or roughly the equivalent of $1 \mathrm{ml}$ of blood. After the intravenous injection of radioactive iron ${ }^{50} \mathrm{Fe}$, the radionuclide is mostly incorporated into circulating haemoglobin. Hence a fall in the wholebody count rate represents loss of blood.

${ }^{1}$ Member, Medical Research Council Department of Clinical Research, University College Hospital Medical School.

Please address requests for reprints to Dr J. Hywel Jones at St Mark's Hospital, London, ECl.

\section{TECHNIQUE}

Details of the procedure were explained to each patient and his permission to proceed with the investigations was obtained. Three to $5 \mu \mathrm{Ci}(0.3$ to $0.5 \mu \mathrm{g})$ of radioactive iron, ${ }^{50} \mathrm{Fe}$, as ferric citrate in isotonic saline ${ }^{2}$, was added to $10 \mathrm{ml}$ of the patient's own plasma under sterile conditions and then left at room temperature for 30 minutes to allow complete binding of the added iron by transferrin. This labelled plasma was then injected intravenously. After allowing a period of 10 days for most or all of this dose to become incorporated in the haemoglobin of the circulating red blood cells, the total body radioactivity due to ${ }^{60} \mathrm{Fe}$ was measured in a whole-body counter.

This counter consists of a movable large-area plastic scintillation detector situated below a lightweight couch. The whole unit is surrounded by a wall of compressed powdered chalk to shield against environmental radiation (Barnaby and Smith, 1967). The patient was counted lying prone and supine with the counter in three different positions in each case. By combination of these readings, counting efficiency can be made relatively insensitive to changes in distribution of radioactivity within the body.

The loss of ${ }^{50} \mathrm{Fe}$ from the body was determined from the difference between the whole-body counts recorded at the beginning and end of each period of investigation. All counts were corrected for radioactive decay and changes in counting efficiency by counting appropriate ${ }^{5} \mathrm{Fe}$ standards. Duplicate $2 \mathrm{ml}$ aliquots of whole blood, taken at the time of each whole-body measurement, were lysed with saponin and counted in a well-type $\mathrm{NaI}$ scintillation counter ${ }^{3}$ to a counting statistical accuracy of 'Supplied by the Radiochemical Centre, Amersham. 'Packard Autogamma. 
$2 \%$. After correcting for radioactive decay of ${ }^{59} \mathrm{Fe}$, the specific activity of whole blood (counts $/ \mathrm{sec} / \mathrm{ml}$ ), averaged over the period between whole-body counts, was determined. This value was used to convert the loss of wholebody counts to an equivalent volume of blood and it was therefore necessary to relate the efficiency of counting a $2 \mathrm{ml}$ blood sample in the $\mathrm{NaI}$ counter to that of counting ${ }^{80} \mathrm{Fe}$ in patients in the whole-body counter. The efficiency with which ${ }^{59} \mathrm{Fe}$ could be counted in patients of various sizes was determined by means of a series of phantoms containing a solution of ${ }^{59} \mathrm{Fe}$. These efficiencies were measured relative to that of a $10 \mathrm{ml}$ reference source counted at the centre of the whole-body counter. The efficiency of counting the $2 \mathrm{ml}$ blood samples was also related to this reference so that whole-body and blood counts could be compared. In practice, $10 \mathrm{ml}$ and $2 \mathrm{ml}$ aliquots of a ${ }^{69} \mathrm{Fe}$ solution were used to calibrate the whole-body counter and $\mathrm{NaI}$ counter, respectively, whenever counting was performed.

In any interval between whole-body counts, the fall in whole-body count rate (A) was converted to an equivalent blood volume $(\mathrm{V})$ by means of the formula:

$$
\mathrm{V}(\mathrm{ml})=\frac{\mathrm{A}}{\mathrm{f}_{1}} \times \frac{\mathrm{f}_{2}}{\mathrm{~B}}
$$

where $f_{1}$ and $f_{2}$ were, respectively, the efficiency of counting ${ }^{59} \mathrm{Fe}$ in the patient and the efficiency of counting a $2 \mathrm{ml}$ blood sample in relation to that of counting the $10 \mathrm{ml}$ reference source. B was the mean count rate per $\mathrm{ml}$ of blood during the period in which the fall in wholebody count rate was $A$.

ACCURACY OF THE TECHNIQUe Since blood loss is estimated indirectly by the difference between two wholebody counts, the accuracy of the method is critically dependent on the precision with which these can be made. For blood losses of less than a litre, the only significant inaccuracy results from the difficulty of reproducing exactly the patient's counting position on different occasions. In 13 patients on whom two separate counts were made on the same occasion, the difference between two counts had an average value of $1.1 \%$ of the mean of the two counts. In individuals, this value had a standard deviation of $1.0 \%$. Thus when considering blood loss from the total blood volume, the majority of errors due to this factor will be less than $2 \cdot 1 \%$ of the total blood volume (ie, about $100 \mathrm{ml}$ ). Although an error arising from the calibration factor $f_{1}$ becomes significant with blood losses over a litre, losses of this magnitude were not encountered in this investigation.

Three further studies were undertaken to check the accuracy of the method. In the first, the whole-body counter was used to measure known volumes of blood withdrawn from three patients with polycythaemia, one patient with haemochromatosis, and one normal subject. When the volumes of blood removed were plotted against the volumes determined by this technique, the correlation coefficient was 0.96 (Fig. 1). The differences between the actual volumes removed and those measured by wholebody counting ranged from +67 to $-66 \mathrm{ml}$, with a mean value of $-4 \mathrm{ml}$.

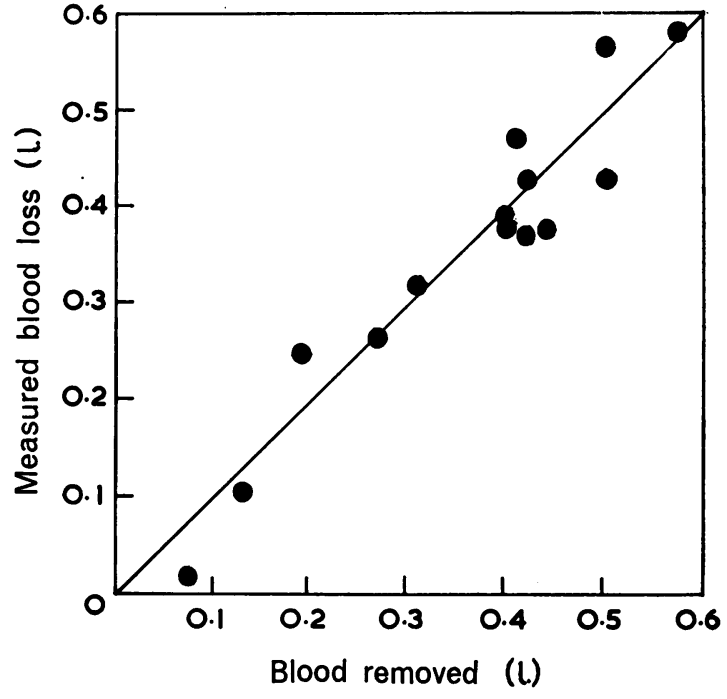

FIG. 1. Volumes of blood removed plotted against wholebody counter measurement of the same volumes to show the distribution about the $45^{\circ}$ line that would be obtained with perfect accuracy.

In three control subjects, all male, who were not suffering from any gastrointestinal disorder, blood loss was studied over a period of four to eight weeks. The results obtained with the whole-body counter, corrected for blood samples removed, were expressed as the mean daily loss and were $1 \cdot 9,2 \cdot 1$, and $2 \cdot 7 \mathrm{ml}$ respectively. These values are within the range of normal estimated by other methods (Roche, Perez-Gimenez, Layrisse, and Di Prisco, 1957; Ebaugh and Beeken, 1959).

The third study consisted of a comparison of the measurement of blood loss over one week using the whole-body counter with that obtained by determination of the faecal excretion of parenterally administered ${ }^{51} \mathbf{C r}$ over the same period. For this purpose, eight patients with colitis were given red blood cells labelled with $30 \mu$ $\mathrm{Ci}$ of ${ }^{51} \mathrm{Cr}$ (as sodium chromate) 10 days after a dose of ${ }^{69} \mathrm{Fe}$. After a further 24 hours, stools were collected for one week. There was a good correlation between the results obtained with the two methods (Table I).

\section{TABLE I}

ESTIMATED BLOOD LOSSES USING THE WHOLE-BODY COUNTER

$\left({ }^{59} \mathrm{FE}\right.$ METHOD) AND THE FAECAL ${ }^{51}$ CR METHODS SIMULTANEOUSLY

\begin{tabular}{|c|c|c|c|}
\hline \multirow[t]{2}{*}{ Patient } & \multicolumn{2}{|c|}{ Estimated Blood Loss ( $\mathrm{ml}$ ) } & \multirow[b]{2}{*}{ Difference in Results } \\
\hline & ${ }^{61}$ Cr Method & "Fe Method & \\
\hline $\begin{array}{l}\text { P.R. } \\
\text { C.G. } \\
\text { J.C. } \\
\text { P.H. } \\
\text { P.E. } \\
\text { P.O'C. } \\
\text { R.M. } \\
\text { M.T. }\end{array}$ & $\begin{array}{r}66 \\
13 \\
51 \\
102 \\
125 \\
520 \\
32 \\
95\end{array}$ & $\begin{array}{r}102 \\
41 \\
68 \\
111 \\
225 \\
527 \\
0 \\
110\end{array}$ & $\begin{array}{rr}+ & 36 \\
+ & 28 \\
+ & 17 \\
+ & 9 \\
+ & 100 \\
+ & 7 \\
- & 32 \\
+ & 15\end{array}$ \\
\hline
\end{tabular}




\section{PATIENTS AND METHOD}

Blood loss was measured in 17 adult patients with ulcerative colitis, of whom six were premenopausal females and 11 were males. In seven, the disease was extensive, involving colon proximal to the splenic flexure; in one, the descending colon, rectum, and sigmoid were affected and nine had proctosigmoiditis. All had had a recent exacerbation of their colitis and had started treatment for this at least $\mathbf{1 0}$ days before the measurement of blood loss was begun.

Measurement of total body radioactivity was repeated at weekly and fortnightly intervals over a period of four to eight weeks. Before each measurement a blood sample was taken to measure the radioactivity. Correction was made for these blood samples and for others removed for laboratory investigations in the final estimation of blood loss. Any phase of study in which non-alimentary blood loss occurred was excluded from the results.

The activity of the colitis at the time of the whole-body counting was assessed by sigmoidoscopic appearances graded according to the criteria of Baron, Connell, and Lennard-Jones (1964). Grade I ('normal') constituted the normal vascular pattern, grade II ('inactive') a nonfriable mucosa without vascular pattern, grade III ('friable') a mucosa with contact but no spontaneous bleeding, and grade IV ('spontaneous bleeding') a mucosa which bled ahead of the sigmoidoscope. Grades I and II are described as 'non-haemorrhagic' and grades III and IV as 'haemorrhagic'. The patients' observations on the presence or absence of blood in the stools were also recorded.

\section{RESULTS}

CORRELATION OF BLOOD LOSS WITH SIGMOIDOSCOPIC APPEARANCES Figure 2 relates blood loss to sigmoidoscopic appearance, where this appearance was constant at the beginning and end of the weekly or fortnightly interval studied. Weekly losses ranged from zero to just over $600 \mathrm{ml}$. There was a rough correlation between the degree of blood loss and the sigmoidoscopic grading in that most patients with a haemorrhagic mucosa (grades III and IV) were losing more than $200 \mathrm{ml}$ of blood per week, whereas in those with a non-haemorrhagic mucosa (grades I and II) the blood loss was usually less than $200 \mathrm{ml}$ per week. In half of the 28 non-haemorrhagic periods studied, blood loss exceeded $50 \mathrm{ml}$ per week and in four instances exceeded $200 \mathrm{ml}$ per week.

CORRELATION OF BLOOD LOSS WITH EXTENT OF COLITIS From the results summarized in Fig. 2, it was not possible to demonstrate a clear correlation between blood loss and the extent of colitis. This diagram excludes blood losses in periods in which the sigmoidoscopic appearance changed during the week or fortnight of observation. When these periods

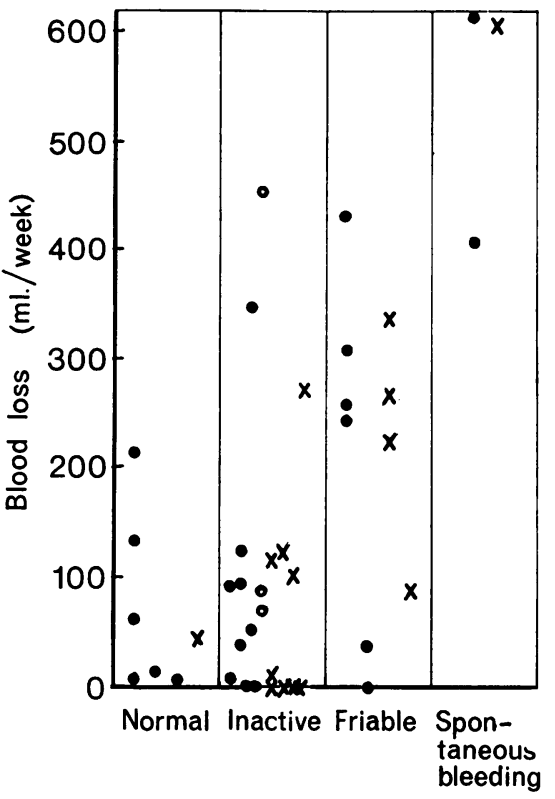

FIG. 2. Blood loss in individual phases related to sigmoidoscopic appearances. The extent of colitis is indicated by symbols:

$\mathrm{O}=$ colitis extending as far as splenic flexure, $\mathrm{O}=$ proctosigmoiditis, $X=$ extensive colitis

are also included and graded as haemorrhagic if the sigmoidoscopic appearance was grade III or grade IV at any time in the period, the average blood loss in the 11 haemorrhagic phases in the patients with extensive colitis was $275 \mathrm{ml}$ per week compared with $193 \mathrm{ml}$ perweek for the 17 haemorrhagic phases in the patients with proctosigmoiditis. In the non-haemorrhagic periods when the sigmoidoscopic appearance was persistently grade I or II, the corresponding values were $72 \mathrm{ml}$ per week for 17 observations in the patients with extensive colitis and $59 \mathrm{ml}$ per week for 23 observations in the patients with proctosigmoiditis. These results suggest that the extent of the colitis does influence the volume of blood lost but not to the same degree as the activity of inflammation in the mucosa.

CORRELATION OF BLOOD LOSS WITH OBSERVED BLOOD IN THE STOOLS Figure 3 relates the measured blood loss to the patients' observations of blood in the stools. It shows that the patients noticed blood in the stools in all except three of the 20 periods when the loss exceeded $200 \mathrm{ml}$ per week. Many patients losing 50 to $150 \mathrm{ml}$ of blood per week, however, did not notice the presence of blood in the stools. Thus patients' statements that there is no blood in their stools do not mean that blood loss is insignificant. 


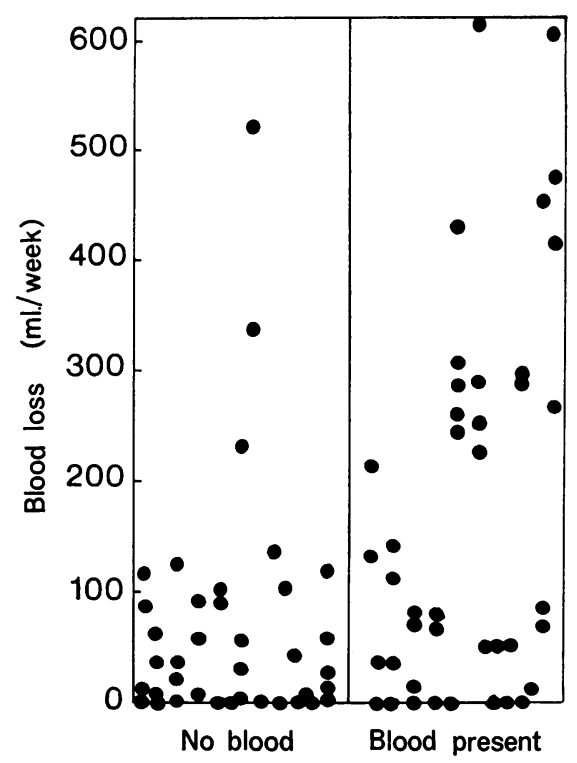

FIG. 3. Patients' observation of blood in the stool related to blood loss during the same period of time.

TABLE II

IRON LOSS IN MEN AND WOMEN DURING PERIOD OF OBSERVATION

\begin{tabular}{llll} 
Age $(y r)$ & Sex & Period of Observation $(w k)$ & Total Iron Loss $(g)$ \\
\hline 47 & F & 6 & $0 \cdot 10$ \\
16 & F & 4 & $0 \cdot 13$ \\
23 & F & 6 & $0 \cdot 18$ \\
30 & F & 7 & $0 \cdot 11$ \\
26 & F & 9 & $0 \cdot 06$ \\
29 & F & 9 & $0 \cdot 86$ \\
17 & M & 8 & $0 \cdot 26$ \\
18 & M & 5 & $0 \cdot 03$ \\
27 & M & 8 & $0 \cdot 16$ \\
29 & M & 7 & $0 \cdot 18$ \\
37 & M & 5 & $0 \cdot 68$ \\
64 & M & 8 & $0 \cdot 26$ \\
54 & M & 4 & $0 \cdot 12$ \\
64 & M & 8 & $0 \cdot 18$ \\
18 & M & 3 & $0 \cdot 26$ \\
24 & M & 6 & $0 \cdot 22$ \\
21 & M & 7 & $1 \cdot 30$
\end{tabular}

CALCULATION OF TOTAL IRON LOSS From the blood loss measurements, the iron loss was calculated and these results are shown in Table II. Over a period of four to eight weeks the total iron loss varied greatly from $30 \mathrm{mg}$ in one patient to $1.3 \mathrm{~g}$ in another. Three patients lost more than $0.5 \mathrm{~g}$ of iron over this period in spite of conventional medical treatment for the colitis.

\section{DISCUSSION}

The present study is the first reported where the whole-body counting technique, in which stool col- lections are not required, has been used to measure blood loss in colitis. The difficulty of obtaining complete faecal collections in clinical work has been emphasized by Callender, Witts, Warner, and Oliver (1966) and this difficulty applies particularly in colitis.

There has been only one previous critical assessment of blood loss measurements using a wholebody counter, that of Holt et al (1967). These authors made 29 measurements of known blood loss between 395 and $520 \mathrm{ml}$ with a mean error of $-12 \%$ and a range from -60 to $+50 \%$. In the present investigation, the mean error of eight measurements over a similar range of blood loss (400 to $500 \mathrm{ml}$ ) has been $-2 \%$ with a range of -14 to $+16 \%$ (in absolute terms, a mean error of $-7 \mathrm{ml}$ with a range of -66 to $+67 \mathrm{ml})$. The principal source of error in the present study arises from minor variations in the patient's counting position on different occasions. With careful positioning of the patients, the error of a single blood loss measurement can be reduced to less than $100 \mathrm{ml}$ in most cases. A second source of inaccuracy arises from the error associated with the calibration factor $f_{1}$, which is a measure of the efficiency of counting ${ }^{50} \mathrm{Fe}$ in a given patient relative to the reference standard. This error is about $5 \%$ of the blood-loss value.

The accuracy of our method has been verified by simultaneous determination of blood loss using the whole-body counter and ${ }^{51} \mathrm{Cr}$ technique in eight patients. The differences in blood loss estimations between the two methods were, with one exception, less than $50 \mathrm{ml}$ and therefore well within the estimated range of error of the whole-body counting technique (Table I). The tendency for the faecal ${ }^{51} \mathrm{Cr}$ method to produce lower values for blood loss probably reflects the difficulty of achieving complete stool collections in patients with severe colitis. Estimation of blood loss in control subjects has also been used to evaluate the accuracy of the method.

In previous studies with the whole-body counter (Price, Forsyth, Cohn, and Cronkite, 1964; Holt et al, 1967), blood loss was calculated from the percentage change in ${ }^{59} \mathrm{Fe}$ retention on the assumption that this was equivalent to the same percentage change of blood volume. For this calculation an accurate assessment of total blood volume was essential. Holt et al (1967) calculated the blood volume in control subjects and iron-deficient patients using a value of $65.6 \mathrm{ml}$ per kilogram of body weight (Wasserman, Yoh, and Rashkoff, 1951). In more recent reports, the normal blood volume has averaged $75 \mathrm{ml}$ per kilogram in men and $66 \mathrm{ml}$ per kilogram in women (Gregersen and Rawson, 1959; Twigg, Nakayama, and Goodwin, 1958). It has also been shown that blood volume correlates poorly 
with body weight as the sole physical parameter and can be predicted more accurately on the basis of a formula including both height and weight (Nadler, Hidalgo, and Block, 1962). The present technique, in which blood loss is estimated directly by measuring the mean concentration of ${ }^{59} \mathrm{Fe}$ in the blood and relating this to the fall in whole-body counts, does not require a knowledge of the blood volume. In this technique it is also unnecessary to measure the red cell utilization of ${ }^{59} \mathrm{Fe}$.

A disadvantage of the whole-body counting technique is the delay (seven to 10 days) before blood loss can be measured. This delay is necessary because soon after injection radioactivity is localized in the bone marrow and later the ${ }^{59} \mathrm{Fe}$ in the red cell mass increases rapidly as the iron is released from the marrow. These changes lead to variation in counting efficiency and to errors in estimating the average concentration of radioiron in the blood (Sargent, 1962). Because of this delay, many of the patients in this study were already improving with medical treatment when measurements were begun. Thus the blood losses in the most severe phases of colitis probably exceeded those measured in this study.

The volumes of blood lost in the present study ranged from 0 to $88 \mathrm{ml}$ per 24 hours, these figures representing the average daily loss over weekly or fortnightly periods. This wide range compares very closely with that of 1 to $89 \mathrm{ml}$ per 24 hours (the average over four days) obtained by Ormerod (1967) using a chemical method of measuring blood loss in the only previous quantitative study of bleeding in active ulcerative colitis. As might be expected the amount of blood lost was influenced both by the activity of the inflammation and the area of mucosa inflamed.

In most $(71 \%)$ of the phases in this study when bleeding exceeded $200 \mathrm{ml}$ per week, the rectal mucosa appeared haemorrhagic on sigmoidoscopy. Of greater interest was the finding that where the mucosa was not haemorrhagic blood loss of more than $50 \mathrm{ml}$ per week was common and on four occasions exceeded $200 \mathrm{ml}$ per week. Blood losses of 50 to $150 \mathrm{ml}$ per week were also measured when patients observed no blood in the stools. These findings are in keeping with the observations of Beal, Skyring, McRae, and Firkin (1963) that on several days two of five patients with colitis in remission had a faecal blood loss in excess of $25 \mathrm{ml}$ per 24 hours.

The present study has shown that iron losses of the order of 0.5 to $1.3 \mathrm{~g}$ may occur over the course of several weeks in an attack of colitis. Since the total iron content of a normal adult averages $5 \mathrm{~g}$, the importance of adequate iron replacement in colitis is evident. In view of the possible impairment of iron absorption in colitis suggested by recent studies (Ormerod, 1968) and the fact that oral iron sometimes aggravates the symptoms, parenteral iron therapy is often the best means of correcting the iron losses.

We are most grateful to Dr J. E. Lennard-Jones for permission to study these patients and for his helpful advice and criticism. We also wish to thank Miss Hilary Eastwood and Mr Philip Cooper for technical assistance.

This article is based on a paper read at the Proctological Section of the Royal Society of Medicine on 23 October 1968, and we are grateful to the honorary editors for permission to publish it here.

\section{REFERENCES}

Bannerman, R. M. (1957). Measurement of gastro-intestinal bleeding using radioactive chromium. Brit. med. J., 2, 1032-1034.

Barnaby, C. F., and Smith, T. (1967). Performance of a large-area whole-body counter. J. sci. Instrum., 44, 499-505.

Baron, J. H., Connell, A. M., and Lennard-Jones, J. E. (1964). Variation between observers in describing mucosal appearances in proctocolitis. Brit. med. J., 1, 89-92.

Beal, R. W., Skyring, A. P., McRae, J., and Firkin, B. G. (1963). The anemia of ulcerative colitis. Gastroenterology, 45, 589-603.

Callender, S. T., Witts, L. J., Warner, G. T., and Oliver, R. (1966). The use of a simple whole-body counter for haematological investigations. Brit. J. Haemat., 12, 276-282.

Ebaugh, F. G., and Beeken, W. L. (1959). Quantitative measurement of gastrointestinal blood loss. II. Determination of 24-hour fecal blood loss by a chemical photospectrometric technique. J. Lab. clin. Med., 53, 777-788.

Finch, C. A. (1964). Physiopathologic mechanisms of iron excretion. In Iron Metabolism, edited by F. Gross, p. 454. Springer, Berlin.

Gregersen, M. I., and Rawson, R. A. (1959). Blood volume. Physiol. Rev., 39, 307-342.

Holt, J. M., Mayet, F. G. H., Warner, G. T., and Callender, S. T. (1967). Measurement of blood loss by means of a whole-body counter. Brit. med. J., 4, 86-88.

Nadler, S. B., Hidalgo, J. U., and Block, T. (1962). Prediction of blood volume in normal human adults. Surgery, 51, 224-232.

Ormerod, T. P. (1967). Measurement of fecal bleeding in active chronic ulcerative colitis. Amer. J. dig. Dis., 12, 1095-1101.

(1968). Radio iron $\left({ }^{\circ} \mathrm{Fe}\right)$ studies in acute ulcerative colitis. Scand. J. Gastroent., 3, 189-192.

Price, D. C., Reizenstein, P. G., Cohn, S. H., Cronkite, E. P., and Wasserman, L. R. (1961). A method for studying iron absorption and loss by whole body counting. (Abstr.) Clin. Res., 9, 165.

—, Forsyth, E. M., Cohn, S. H., and Cronkite, E. P. (1964). The study of menstrual and other blood loss, and consequent iron deficiency, by ${ }^{50} \mathrm{Fe}$ whole-body counting. Canad. med. Ass. J., 90, 51-54.

Roche, M., Perez-Gimenez, M. E., Layrisse, M., and Di Prisco, E. (1957). Study of urinary and fecal excretion of radioactive chromium $\mathbf{C r}^{51}$ in man. Its use in the measurement of intestinal blood loss associated with hookworm infection. J. clin. Invest., 36, 1183-1192.

Sargent, T. W. (1962). Metabolic studies with ${ }^{50} \mathrm{Fe},{ }^{47} \mathrm{Ca}$ and ${ }^{11} \mathrm{C}$ in various diseases. In Whole-body Counting. Proceedings of the Symposium, Vienna, 1961, pp. 447-466. International Atomic Energy Agency, Vienna.

Twigg, H., Nakayama, L., and Goodwin, P. (1958). Blood volume studies in humans using radioiodinated human serum albumin. Maryland Med. J., 7, 150-154.

Wasserman, L. R., Yoh, T. F., and Rashkoff, I. A. (1951). Blood volume determination: comparison of T-1824 and $\mathrm{P}^{32}$ labelled red cell methods. I. Lah. clin. Med., 37, 342-352. 